\title{
Effectiveness of Online Training In Indian IT Industry
}

\author{
Dr. Amita Maxwell \\ [Assistant Professor] \\ Department of Human Resources, Joseph School of Business Studies-SHIATS, Deemed University, Allahabad \\ Uttar Pradesh-211007, India \\ Email: amita.maxwell@shiats.edu.in
}

\begin{abstract}
Technologies have great potential benefit to offer learning and training however this is a complex multifaceted area. Technology based training represents a new recent pedagogical paradigm. While it's still in its infancy, training on the internet is already a reality. Surveys conducted by leading global market research firms have indicated that online learning and training will follow an upward moving graph and that more and more organizations and individuals will implement this mode of training. Though BPO industry is of recent origin in India it has attracted the attention of entrepreneurs and policy makers due to its phenomenal growth. Hence the present study contemplates to find the present status of online training in BPOs, so as to check its effectiveness, potential benefits which firms derive from online training, why firms should implement online training, the limitations of online train ing. NASSCOM compiles a list of BPO companies registered with it, which was used for the selection of the sample; a purposive sample of 25 BPO companies has been drawn for the study. Managers and training departments need to determine when and if online training is a viable strategy. Organizations today realize that they cannot use traditional training methods if they want to stay competitive. Because product cycles, competitive intelligence, industry information and corporate strategies are moving and changing much faster than they need to; companies understand that the only way to get knowledge to their employees is through technologically mediated virtual training and learning.
\end{abstract}

KEY WORDS: Online Training, Business Process outsourcing, Traditional Training, Blended Learning, Behavioral and Emotional Training, Training in IT Industry

\section{I.INTRODUCTION}

Traditional training has been in use since a very long time. This is an old method of training and organizations extensively rely on this method. With changes happening in every area of organizational functioning, training of employees is no exception. A paradigm shift can be witnessed in the area of training in the recent years. The tool or instrument for such a change can be attributed to "technological advancements", technology has altered the landscape of corporate learning as well. Technological changes have facilitated training to be delivered with convenience and flexibility. This paradigm shift has led to companies rethinking on new ways to keep employees update; keep up with rapid increase of learning that must take place to remain competitive as remaining competitive is a priority today for organizations. Hence we find companies shifting from traditional training towards "online training" to train, up-skill or re-skill their workforce.

\section{II.OBJECTIVE AND METHODOLOGICAL OVERVIEW}

Online training is still in its nascent stage and one needs to understand the application and scope of this type of training. NASSCOM compiles a list of Business Process Outsourcing companies (BPO) registered with it, which was used for the selection of the sample; a purposive sample of 25 BPO companies has been drawn for the study. The study concentrates mainly on one major service line viz, customer care (This segment consists of mainly telephone based centers, or call centers, performing specific customer-centric activities). Within customer care voice based work accounts for over $60 \% .^{1}$ The size of the customer care segment in India is close to $50 \%$ of the total industry size. ${ }^{2}$ The survey covered all major locations viz Bangalore, Mumbai-Pune, and Delhi-Gurgaon regions, Hyderabad and Chennai. As the present study pertains to evaluating effectiveness of online training in BPOs, only those BPOs have been chosen that are imparting online training to their employees. Performance review questionnaire was used to measure behavioural changes of trainees as result of training when back on job. Data was collected from 25 BPOs both for online and traditional training.

with a respondent sample size of 100 each for traditional and online training. The focus of the study is Indian Information Technology (IT) Industry particularly with reference to BPOs or Call Centers. The objective of the study is as follows:

1. To find the present status of online training in BPOs

2. To check the effectiveness of online training in BPOs

\section{III.ONLINE TRAINING VERSUS TRADITIONAL TRAINING}

Online training is the latest developments in the area of training and learning, although still in a nascent stage, companies are realizing and testing its potential and is emerging as one of the fastest growing methods of training. There are certain factors which clearly point out to the growing popularity of online training and the

\footnotetext{
${ }^{1} \mathrm{http}: / /$ www.bpoindia.org

${ }^{2}$ Ibid.
} 
benefits which accrue to the company adapting online training over traditional methods of training.

1. Flexibility

2. Convenience

3. Savings to companies

4. Trainee Centered/Focused Approach

5. Cost-Effective

6. Interactive

Traditional methods of training provide the benefit of instructor interface or a human and personal touch with the instructor/trainer. This is not needed for all types of training as training needs differ. With technological modernization this personal or human touch is also possible in online training as in physical classroom. Online training can be "live" or "synchronous" hence giving scope to trainees to get into conversation sessions with trainers. Hence there is virtual presence of trainer and technological interface makes it possible.

\section{WHY ONLINE TRAINING}

The potential of online training as an effective training method is yet to be tested much of its effectiveness depends on how it is delivered and designed. Training needs in BPO's differ as BPO employees require unique skill-sets to perform the task. An attempt has been made to check the status of online training in BPO companies and if online training provides an effective method of training as compared to traditional training.

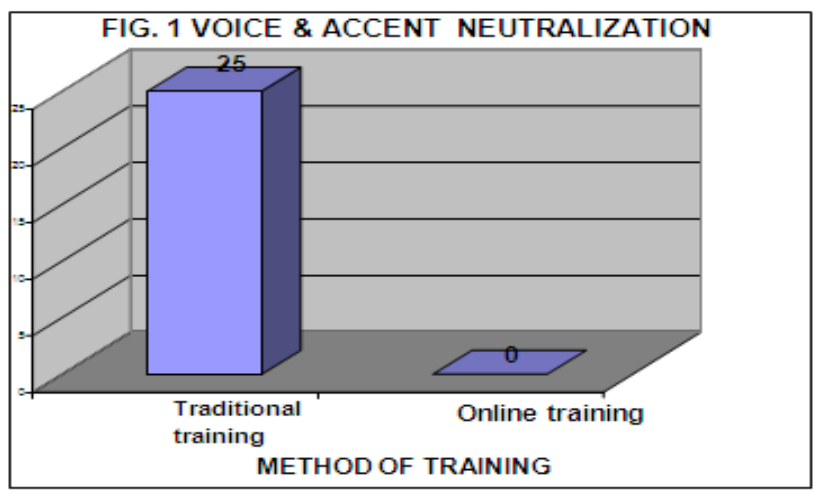

Fig 1. Shows that BPO's rely only on traditional training (delivered in class room settings and instructor-led) as compared to online training for Voice and accent Neutralization training. Traditional training dominates in this area as there is need for demonstration and high hands-on experience which cannot be provided by online training.

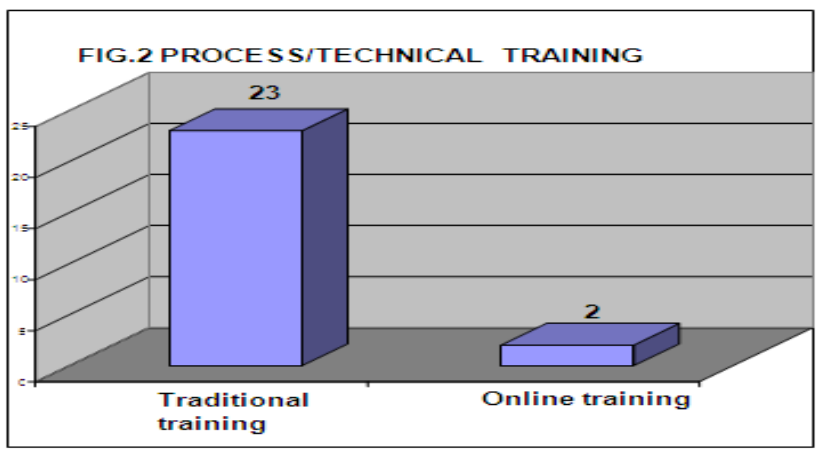

Fig. 2 .Shows BPOs rely heavily on traditional training for process/technical training as compared to just use online training for this kind of training showing significantly greater use of traditional training as compared to online training.

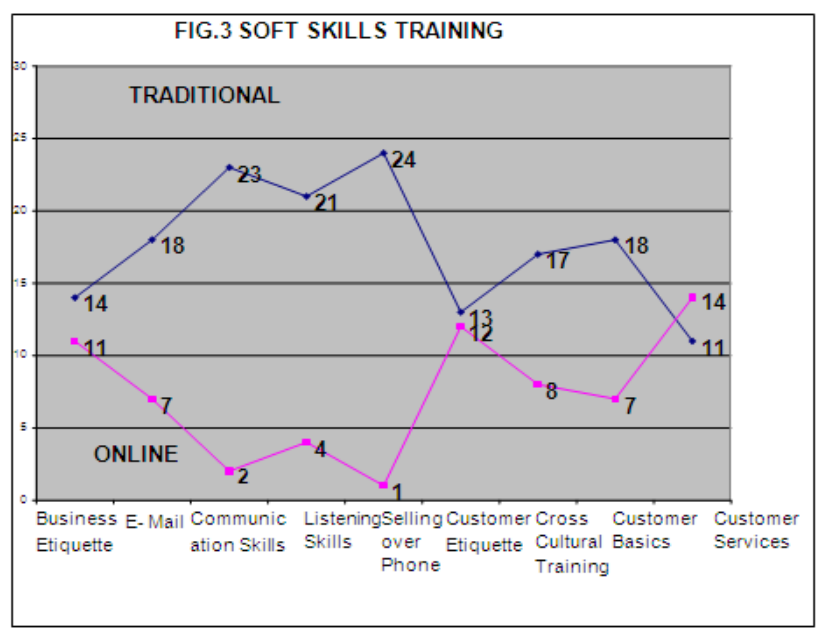

Fig.3.shows the proportion of traditional and online training methods being used by BPOs for different areas of soft skills training showing higher preference for traditional training for soft skills training and moderately, but higher preference for online training in areas of cross cultural training, customer basics and customer services.

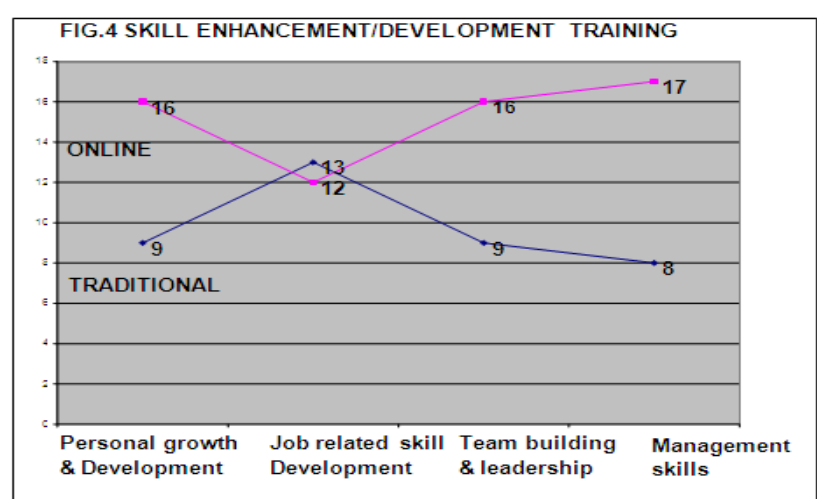

Fig.4. Shows the proportion of traditional and online training used for different types of skill Enhancement/Development training, the proportion of traditional training is lower as compared to online training.

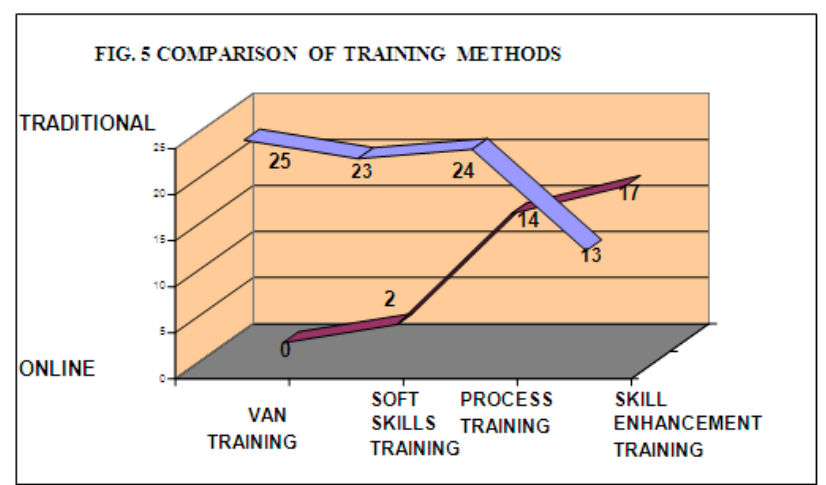

Fig. 5. Shows the proportion of traditional and online training for the four important types of training in BPOs, for Voice and Accent Neutralization training (VAN), traditional training is solely used, the proportion of 
traditional training is significantly high for soft skills and process training, the proportion of online training is high for skill enhancement training/development training.

Table 1 Comparison Of Traditional And Online Training

\begin{tabular}{|c|c|c|c|c|c|c|}
\hline \multicolumn{4}{|c|}{ TRADITIONAL TRAINING } & \multicolumn{3}{|c|}{ ONLINE TRAINING } \\
\hline CODE & ME. $+\mathrm{N}$ & MEDIAN & MODE & IE.AN & IEDLAN & MODE \\
\hline 1 & 5.773 & 6 & 5 & 6.608 & 7 & 7 \\
\hline 2 & 6.215 & 7 & 6 & 7,709 & 8 & 8 \\
\hline 3 & 5.852 & 6 & 5 & 7,010 & 7 & 7 \\
\hline 4 & 6.040 & 6 & 6 & 7.363 & 8 & 8 \\
\hline 5 & 4.757 & 5 & 5 & 7.07 & 7 & 7 \\
\hline 6 & 6.070 & 6 & 6 & 6.705 & 6 & 7 \\
\hline 7 & 4.970 & 5 & 5 & 7.709 & 8 & 8 \\
\hline 8.1 & 6.161 & 6 & 5 & 7.636 & 8 & 8 \\
\hline 8.2 & 5.909 & 6 & 6 & 7.709 & 8 & 8 \\
\hline 8.3 & 4.787 & 5 & 5 & 6.688 & 7 & 7 \\
\hline 8.4 & 4.757 & 5 & 5 & 7.010 & 7 & 7 \\
\hline 8.5 & 6.010 & 6 & 6 & 7.363 & 8 & 8 \\
\hline 8.6 & 5.666 & 6 & 6 & 7.373 & 7 & 7 \\
\hline 8.7 & 5.852 & 6 & 5 & 7.787 & 8 & 8 \\
\hline 8.8 & 5.490 & 5 & 5 & 6.983 & 7 & 7 \\
\hline 8.9 & 5.010 & 5 & 5 & 6.212 & 7 & 7 \\
\hline
\end{tabular}

In table 1 intervention codes 1 to 8.9 have been used for question numbers 1 to 8.9 in performance review questionnaire to measure whether trainees are able to apply or put their learning into effect when back on the job after completion of traditional and online training in the same training area. Question No. 1 to 7 have been used to measure behavioural changes as a result of training. In Question No. 8.1 to 8.9 the team leaders/operation managers were asked to rate on a ten point scale, measures that would typically be business or organizational key performance indicators with respect to trainees. Statistical values for the data have been computed as shown in the above table. Hence it is concluded that online training outcomes are favourable and effective in meeting organizational goals and application of new skills learnt from training to job settings when back on job.

\section{BEHAVIOURAL ISSUES IN ONLINE TRAINING}

Some training programmes focus on emotional and behavioural learning. In behaviourally experienced training trainees can learn about behavior by role playing, in which the role players attempt to act their part in respect of a class, as they would behave in a real life situation. Role Playing generally focuses on emotional (mainly human relations) issues rather than actual ones. The essence of role playing is to create a realistic situation, as in case study, and then have the trainees assume the parts of specific personalities in the situation. For example, a male worker may assume the role of a female supervisor, and the supervisor may assume the role of a male worker. Then, both may be given a typical work situation and asked to respond as they expect others to $\mathrm{do}^{3}$. The consequence is a better understanding among

${ }^{3}$ William B. Werther and Keith Davis, op.cit., p. 261 individuals. Role Playing helps promote interpersonal relations. Attitude change is another result of role playing. Role playing can be an enjoyable and inexpensive way to develop many new skills. The role players can also give up their inhibitions and experiment with new ways of acting. Role playing also trains a person to be aware of and sensitive to the feelings of others. Business games, cases, incidents, group discussions and short term assignments are used as learning methods. Sensitivity training or laboratory training is an example used for emotional learning. Sensitivity training is a method for increasing employees' insight into their own behaviour by candid discussions in groups led by special trainers. It aims to increase trainees' insights into their behaviour and the behaviour of others by encouraging an open expression of feelings in the trainer-guided T-Group "laboratory" (the $\mathrm{T}$ is for training). The objectives of sensitivity training are to provide the participants with increased awareness of their own behaviour and how others perceive them-greater sensitivity to the behaviour of others, and increased understanding of group processes. Although there is a larger issue of effectiveness of online training for behaviorally targeted courses in the soft skills/business skills arena, still some organizations are using online training in this training area, there is resistance about how to deeply impact trainees. In addition to using e learning in the training of IT skills, a growing number of businesses have used E learning in the training of business and soft skills. Soft skills' training is currently growing at twice the rate of information technology training ${ }^{5}$. At Nestle, for example, E learning is used to train employees on communication teamwork, and leadership skills ("Nestle" widens course offers, 2004) and Bank of America uses E learning for interpersonal skills training. ${ }^{7}$ Some of the most common business and soft skills taught include management, leadership, communication, customer service, quality management and HR skills. ${ }^{8}$ All these skills have traditionally been taught in class room settings. These skills involve the development of verbal and non verbal skills that have traditionally been trained face-to-face. Pure computer based programs cannot provide the face-to-face interaction that class room training offers; as a result it has been argued that the use of E learning for soft skills training is unsuitable. Nevertheless, we can find online methods being used in soft skills areas as well though primarily as supplemental material to the face-to-face training.

4 Based on J.P. Campbell and M.D. Dunnette, "Effectiveness of T-Group Experiences in Managerial Training and Development," Psychological Bulletin, Vol. 7 (1968), pp.73-104.

${ }^{5}$ National Governors Association, 2001; Urdan \& Weggen, 2000.

6 "Nestle" widens course offers for all its staff. 2004. IT

Training, May: 11.

${ }^{7}$ Dobbs. K. 2000. What the online world needs now: Quality Training, 37: 84-94.)

${ }^{8}$ Skillsoft, 2001. E-learning in USA \& Canada benchmark survey. Nashua, OH: Author 


\section{CONCLUSION}

With the need to stay competitive globally, companies need to keep employees update and this is possible only with online training. The cost-effectiveness and time savings with online training serves as an advantage. Enriched learning experience makes learning easier, reduced stress with learning and training, multifaceted communication tools that allow individuals to collaborate in real time, digitization, automation and virtualization, consistent quality of training, scalability and standardization which is difficult to obtain from any other form of training are the most prominent factors tilting companies towards online training method.

Online training provides a better learning and training experience as compared to the other modes of training due to its flexibility, convenience and enriched learning experience which can be created with the help of stories, animations, clippings, videos, audio-visual effects which makes learning easier and reduces the stress with learning and training. Nevertheless there are certain factors which favour the use of traditional training especially for areas where high hands-on-experience or demonstration by the instructor is needed for example voice and accent neutralization training and process/technical training and dealing with emotional or behavioral issues for such topics traditional training compares better to online method.

The issue is not about replacing traditional with online but using online training in areas where it has the potential of being used as a viable or effective training method because of the benefits it promises to the organization. Lastly, online training's viability, effectiveness, and potential to return tangible benefits to organizations depends largely on how it is designed, delivered and evaluated. Organizations should turn towards blended learning (a combination of online training and other training media) rather than online training alone. With respect to the use of online training, in particular, blended learning has been used to refer to "training that combines traditional class-room sessions with e-learning and selfstudy." "The idea of blended learning makes sense as it appeals to the needs and learning styles of a variety of trainees. ${ }^{10}$ This approach is likely to have the benefits of increasing trainee satisfaction with online training as well as enhancing trainee learning. One company that has had tremendous success aligning its online learning strategies with employee preferences is Hewlett-Packard (HP), because HP's motto for training a global workforce is "one size does not fit all", it allows its regional trainers in countries around the world to select the best delivery modes for training their employees. ${ }^{11} \mathrm{HP}$ has found that employee preferences for online learning (and other

\footnotetext{
${ }^{9}$ Kovaleski, D. 2004. Blended learning in focus Corporate meetings \& incentives, 23: 35-36.

10 Thomson NETg. 2003. Thomson job impact study-final results-the next generation of corporate learning: Achieving right blend. Naperville. IL: Netg.

${ }^{11}$ O' Leonard. K. 2004. HP case study: Flexible solutions for multi- cultural learners. Ooakland, CA: Bersin \& Associates.
}

training media) differ considerably around the world. These variations in online learning preferences suggest that a single type of online training program may not meet the needs and expectations of all employees. So as to make training program flexible and may lead to an improvement in trainee performance during online learning.

\section{REFRENCES}

[1] Alexander Laurel, "Online Training”, Mumbai: Jaico Publishing House $2^{\text {nd }}$ Edition 2008.

[2] Campbell, J.P. (1971), "Personnel training and development", Annual Review of Psychology, 22, 565-602.

[3] Curtis, J., Bonk. (2000). "Online training in an online world", Jones knowledge, Inc. and course Share.com. http://www.jonesknowledge.com.

[4] Curtis J. Bonk, "Online Training in an online world" 2002, available at JonesKnowledge,Inc. and CourseShare.com.

[5] DeRounin, R.E., Fritzsche, B.A., \& Salas E., "E-learning in Organizations", journal of Management, Vol 31, No. 6, December 2005.Available at http://jom.sagepub.com.

[6] Nestle widens course offers for all its staff, 2004. IT Training May: 11. The new book of e-learning and blended strategies. 2004. KM Review.

[7] NASSCOM Annual Report 2009. http://www.nasscom.org.

[8] NASSCOM, 2002 Perspective 2020: "Transform Business Transform India” 2009.

[9] National Association of Software and Service Companies (NASSCOM) Strategic Review 2009.

[10] O'Leonard. K. 2004. HP case study: flexible solutions for multi-cultural learners. Oakland, CA: Bersin \& Associates.

[11] Online Learning News. (2001a). Blending and Spending. Online Learning News 4(13). Retrieved February 17, 2002 from: http://www.vnulearning.com

[12] Thomos NeTg. 2003. Thomson job impact study- final results- the next generation of corporate learning: Achieving the right blend. Naperville. IL: Netg.

[13] Van Buren, M.E., \& Erkskine, W. (2002). The 2002 ASTD state of the industry report, Alexandria, VA: American Society of Training and Development.

[14] Wexley, K.N., \& Lathman, G.P. (1991), Developing and training human resources in organizations, New York: Harper Collins, $2^{\text {nd }}$ edition.

[15] Williams, G. (1976) "The Validity of Methods of Evaluating Learning", Journal of European Industrial Training. 